\title{
QUALITY ASSESSMENT OF BITUMINOUS BINDERS BASED ON THE VISCOELASTIC PROPERTIES: POLISH EXPERIENCE
}

\author{
Piotr RADZISZEWSKI, Karol J. KOWALSKI, Jan B. KRÓL, \\ Michał SARNOWSKI, Jerzy PIŁAT \\ Faculty of Civil Engineering, Warsaw University of Technology, Al. Armii Ludowej 16, 00-637 Warsaw, Poland
}

Received 28 Apr 2013; accepted 13 Jun 2013

\begin{abstract}
Construction of modern and durable bituminous pavements requires high quality bituminous binder, aggregates and additives. The main objective of this paper was to analyse and compare viscoelastic properties of unmodified and polymer modified bitumens produced in Poland, Europe, in order to assess their quality. In this paper there are presented results of bituminous binder European classification tests (penetration, softening point and Fraass breaking point) as well as rheological test results conducted over a wide range of temperatures. In addition, image analysis of the microstructure of selected polymer modified bitumens is also presented. Based on the analysis it was concluded that although bituminous binders complies with European specification requirements, they are significantly different in terms of their rheological properties. It was found that regardless of binder producer, bituminous binder within the same hardness group exhibit different low and high temperature properties.
\end{abstract}

Keywords: bituminous binder, low temperature properties, viscoelastic properties, penetration.

Reference to this paper should be made as follows: Radziszewski, P.; Kowalski, K. J.; Król, J. B.; Sarnowski, M.; Piłat, J. 2014. Quality assessment of bituminous binders based on the viscoelastic properties: Polish experience, Journal of Civil Engineering and Management 20(1): 111-120. http://dx.doi.org/10.3846/13923730.2013.843586

\section{Introduction}

A basic bituminous binder function in HMA is to durable cover and connect aggregates in a monolith composite with desired properties, e.g. rutting, fatigue and low temperature cracking resistance (Read, Whiteoak 2003).

Polish experience in binder selection and HMA mix design process changed drastically over last 20 years' time period. The same scale of growing asphalt market is noted on other Baltic countries (Sivilevičius, Šukevičius 2009). At the beginning of the 1990 's, due to the significant traffic increase and hot summers, rutting started to be a major problem (Radziszewski 2007). In order to avoid this problem, new technologies with lower amount of harder binder were introduced. As a result, number of rutting defects was limited, but low temperature cracking started to be an issue. As a next step, polymer modified bitumen with extended temperature range of viscoelastic properties was used in increasing number of road contracts (Pilat, Radziszewski 2010). Currently, Poland is a European leader in terms of a number of a pavement construction projects (Radziszewski et al. 2012). On-going construction and re-construction program includes works on a various types of roads: from local to the trans-European corridors. Construction needs are in keeping with the growing Polish economic situation and European transportation infrastructure requirements (e.g. axle loads of up to $115 \mathrm{kN}$ ).

All around the world, there are currently three systems used to classified bituminous binder: penetration grade system (main system used in Europe), performance grade system (used mainly in the USA) and viscosity grade system - currently rarely used. In Poland, as it takes place in EU area, European specifications for bituminous binders and hot mix asphalt are observed. According to those specifications, bituminous binders are classified based on the penetration value at $25{ }^{\circ} \mathrm{C}$ and softening point. In addition, there is a separate specification for unmodified bituminous binder (EN 12591 (2009) Specifications for Paving Grade Bitumen) and for polymer modified bituminous binders (EN 14023 (2010) Bitumen and Bituminous Binders - Specification Framework for Polymer Modified Bitumens). Currently for the road construction in Poland most commonly are used unmodified bitumens 20/30, 35/50, 50/70 (where 20/30 is a penetration range) and polymer modified bitumens PmB 25/5560 and $\mathrm{PmB} 45 / 80-55$ (where 25/55 is penetration rang

Corresponding author: Piotr Radziszewski

E-mail: p.radziszewski@il.pw.edu.pl 
and 60 is a softening point). In the near future synthetic and bio binders probably will be used for road construction as a sustainable alternative for conventional binder (Gaweł et al. 2010).

As first, it should be highlighted, that history of polymer modified bitumen use in Europe and in the USA is much different, and similarly as the specification for bituminous binder properties are different. Superpave specifications prepared as one of the results of the Strategic Highway Research Program (SHRP) are almost 20 years old. Research part of this project was conducted from 1987 to 1992 while up to now Superpave specifications, although commonly used in the USA, are under further verification and improvement process (McDaniel et al. 2011). Main idea of the Superpave, differently than European specifications, is to relate binder properties with climatic region when the binder will be applied (McGennis et al. 1994). Together with that, Superpave specifications does not have requirements to the bituminous binder composition and origin, which allows binder producers to modify bituminous binder in an "open way", those accelerating development of the binder modification technologies (Bahia et al. 2001; D’Angelo 2010).

Superpave requirements were initially prepared for the medium traffic volume and speed and the idea was to include higher traffic and/or slower speed by bumping up binder performance grade. Bumping by $12{ }^{\circ} \mathrm{C}$ (from PG 58 to PG 70) requires from binder producers stiffening of the binder, e.g. by high level of modification. This, in turn, increases the binder cost and requires higher technological temperatur. In Europe, however, such a high level of binder modification is typically not accomplished, but more popular is application of hard binder (typically due to oxidization process) with penetration of $20-50$ at $25^{\circ} \mathrm{C}$; binders with such a penetration can be compared to Superpave PG 82 binders (Eurobitume 2011).

Second problem recognized during increasing of the upper performance grade is a lack of the test method "sensitive" for the modification process. In the USA, in order to stiffen upper PG and produce economically attractive binders, non-polymer based modifiers started to be used. This finished with, in some cases, meeting Superpave specifications without expected improvement of the HMA (and those bituminous pavement) properties. In practice, value of the $\mathrm{G}^{*} / \sin \delta$ is highly related to the complex modulus and less to the phase angle. But, it is widely known that properties of bitumen are generally and conveniently represented in terms both of complex modulus magnitude and phase angle master curves (Yusoff et al. 2011). For most practical applications, that characterization of bitumen rheological properties in range of temperatures from $-30{ }^{\circ} \mathrm{C}$ to $90{ }^{\circ} \mathrm{C}$ is usually sufficient (Behzadfar, Hadzikiriakos 2013). Beneficial property of bituminous binders modified with elastomeric polymers above traditional binders is the increase of elasticity not related to the stiffness, but highly connected to the phase angle (D'Angelo 2010; Slowik 2012).
Application of the stiff (hard) bituminous binder in Europe in order to prevent rutting, however, results in decreasing of the low temperature properties. Binders used in Europe with an upper PG of 82 typically exhibit critical temperature of $-6{ }^{\circ} \mathrm{C}$ to $-12{ }^{\circ} \mathrm{C}$. For the Polish (and Middle European) binders critical temperature is determined mainly by the $m$ parameter (obtained during testing in bending beam rheometer) and resistance to aging while stiffness parameter $S$ is typically secondary important (Piłat et al. 2009). In other words: critical temperature obtained according to the Superpave requirements is much different when $m$ or $S$ parameter is analysed (as it is more discuss later in the Test section of this paper). In addition, original Superpave methodology was questioned and has been recently renewed resulting with new test methods, e.g. Asphalt Binder Cracking Device ABCD test protocol (AASHTO TP 92-11 2011).

Binder classification system used in Europe does not provide sufficient amount of the information regarding viscoelastic properties. More over control system used during HMA production such as sample taking and investigating method are expensive and time consuming (Bražiūnas, Sivilevičius 2010).

Due to this reason, more advanced rheological tests are sometimes beneficial to have a wider picture of the bituminous binder properties.

\section{Problem statement and objectives}

Based on the literature review, authors' personal experience and initial tests it was found that bituminous binders currently used in Poland, although typically satisfying specification requirements may not provide adequate low temperature properties. In addition, same type of binder from same producer may have diverse rheological properties when tested at different time over the construction season.

The objective of this study was to evaluate quality (based on the viscoelastic properties) of unmodified and polymer modified bituminous binders produced in Poland by refineries in Płock and Gdańsk.

\section{Materials and testing methods}

During this study Polish market of hot mix asphalt producers was investigated. HM plants were divided based on the geographical location and bituminous binder type used. Binder samples were obtained from north-east, central, south and south-west part of the country. In this study $29^{\text {th }}$ different binder samples were acquired. Not every type of binder was available in asphalt plant during sampling which was the reason for varying the quantities of delivered samples. Each sample (10 kg weight) was obtained according to EN 58 (Bitumen and Bituminous Binders - Sampling Bituminous Binders) specification during binder unloading when transported to the HMA plant. Samples were collected during the construction season of 2010, from April to November in according 
to EN 58 method to ensure homogeneity and type of the bitumen. Collected binder samples were produced by two main Polish bituminous binder producers, coded here as $\mathrm{A}$ and B. Bitumens produced in Poland are obtained from Russia crude oil. Total amount of collected samples was as follows:

- unmodified bitumen 20/30: four samples;

- unmodified bitumen 35/50: eight samples;

- unmodified bitumen 50/70: seven samples;

- polymer modified bitumen PmB 25/55-60: five samples;

- polymer modified bitumen PmB 45/80-55: five samples.

Calculations were conducted within described scope of the research and were limited to standard deviation and mean calculations. At this level of research, deeper statistical analysis were not implemented due to the high range of various bituminous types tested (35/50, 50/70, etc.). Goal of those tests was to compare results in same binder groups. Number of samples was not high enough for the complex statistical analysis.

It has to be noted, that according to the European requirements, bituminous producers providing polymer modified bitumen $(\mathrm{PmB})$ does not have to characterize type of the polymer used and its content. Although that technological information is not publically available, in most of the cases typical polymers used during production of PmB in Poland are SBS elastomers in the content of $3-5 \%$.

Until testing, samples were stored in $+5{ }^{\circ} \mathrm{C}$ conditions to prevent aging process. Samples were tested in order to study their basic (classification) and rheological properties:

- penetration at $25{ }^{\circ} \mathrm{C}$ according to EN 1426 (2007);

- softening point according to EN 1427 (2007);

- elastic recovery according to EN 13398 (2010);

- dynamic shear according to EN 14770 (2012);

- flexural creep stiffness according to EN 14771 (2012).

Properties of unmodified and polymer modified bitumen were obtained for non-aged as well as short-term (RTFO - Rolling Thin Film Oven) and long-term (PAV Pressure Ageing Vessel) aged samples. In addition group composition of binders and polymer microstructure in according to EN 13632 (2010) and method developed by Król (2008) were investigated. Due to the space limitation only selected test results are presented here while full data set is available in the report (Radziszewski et al. 2011).

Properties of bituminous binders were evaluated according to PN-EN 12591:2010 and PN-EN 14023:2010 specifications. Test results obtained from BBR (Bending beam rheometer) and DSR (Dynamic share rheometer) apparatus were evaluated according to the US specifications (ASTM D6373-13 Standard Specification for Performance Graded Bituminous Binder (2013)).

\section{Test results}

During the study basic classification and advanced rheological test were conducted together with the microstructure image analysis and fractional analysis.

\subsection{Classification tests}

Penetration test is a good measure of the binder consistency in medium temperature and is a most basic classification test method (according to EN 12591 (2009) specification).

Results of binder penetration tests conducted at $25{ }^{\circ} \mathrm{C}$ are shown in Figure 1 for unmodified bitumen and in Figure 4 for polymer modified bitumen. It can be noticed, that for the same binder type (e.g. 50/70) results are diversified but except some limited cases, binders met requirements. In figures the level of requirements was marked by dashed lines and the mean value of the results was marked by the horizontal red line. When results are analysed in terms of the producer, high diversity is shown for the producer B.

Figures 2 and 5 show results of softening point determination according to the Ring and Ball method. This test method is a good measure of the binder and HMA resistant to the high temperature damages (rutting).

Test results for the unmodified bitumen are less diversified within the same binder type as it happens for the polymer modified bitumen. One of the tested PmB 25/55-60 does not meet requirements. For the same binder group the highest differences were obtained. It can be

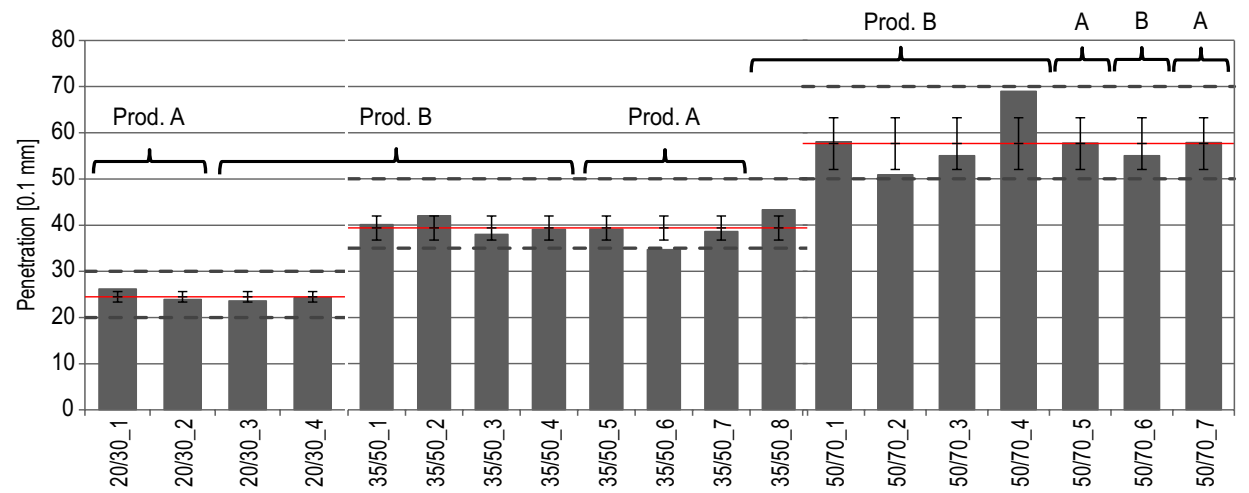

Fig. 1. Unmodified bitumen penetration at $25^{\circ} \mathrm{C}$ 
noticed, that unmodified bitumen demonstrates $10{ }^{\circ} \mathrm{C}$ lower softening point (for the binder groups with the similar consistency/penetration). It can be further concluded, that polymer modification is a good way to improve high temperature resistance of bituminous binder.

Fraass breaking point results are shown in Figures 3 and 6. It can be noticed, that in this "Fraass temperature" binder does not completely loses its viscous properties. The actual cracking temperature can be much lower (up to $20{ }^{\circ} \mathrm{C}$ ).
For the selected bituminous groups (divided based on binder hardness) large diversification of test results was recognized: up to $9{ }^{\circ} \mathrm{C}$. This fact shows significant differences between "theoretically" similar binders. It is especially noticeable for modified bitumen. However, it has to be noticed that modified bitumen presents lower, more favourable cracking temperatures.

Elastic recovery testing is a basic test utilized to evaluate bitumen modification. Elastic recovery test results are presented in Table 1 .

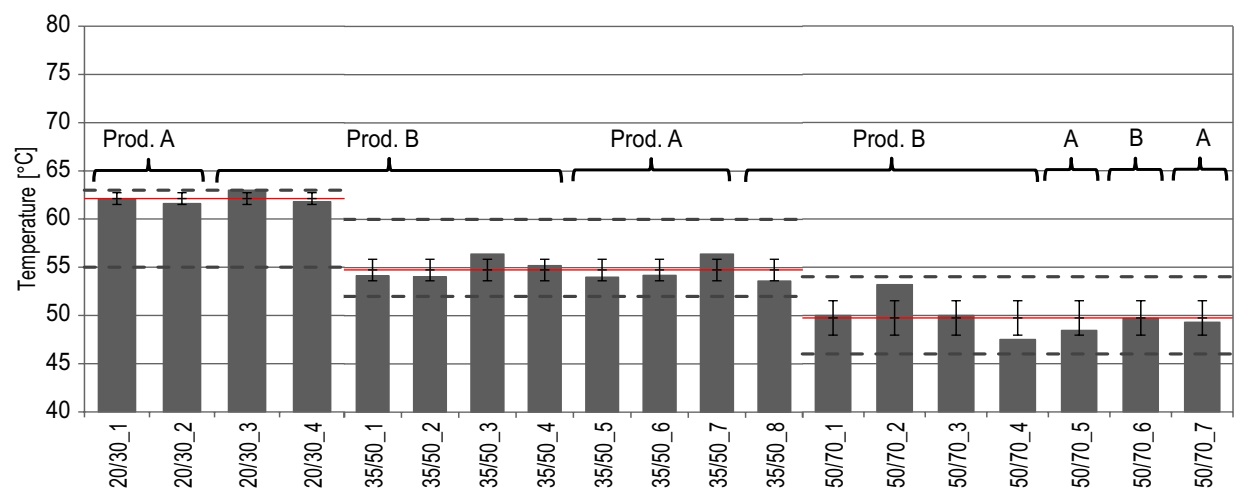

Fig. 2. Unmodified bitumen softening point

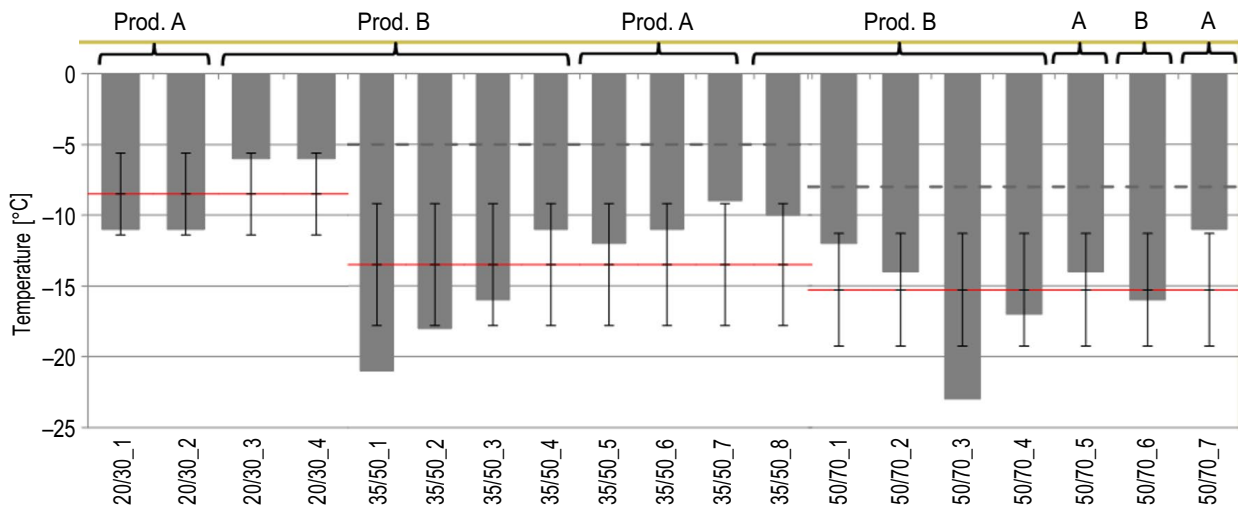

Fig. 3. Unmodified bitumen Fraass breaking point

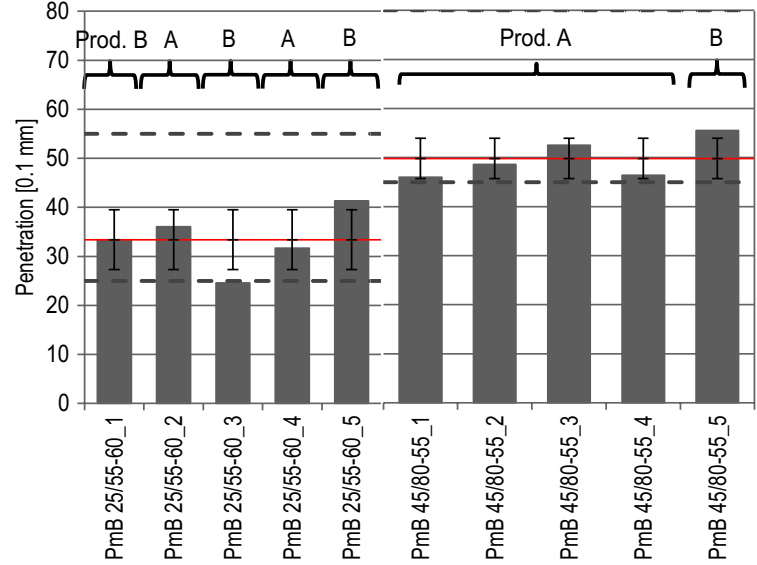

Fig. 4. Polymer modified bitumen penetration at $25^{\circ} \mathrm{C}$

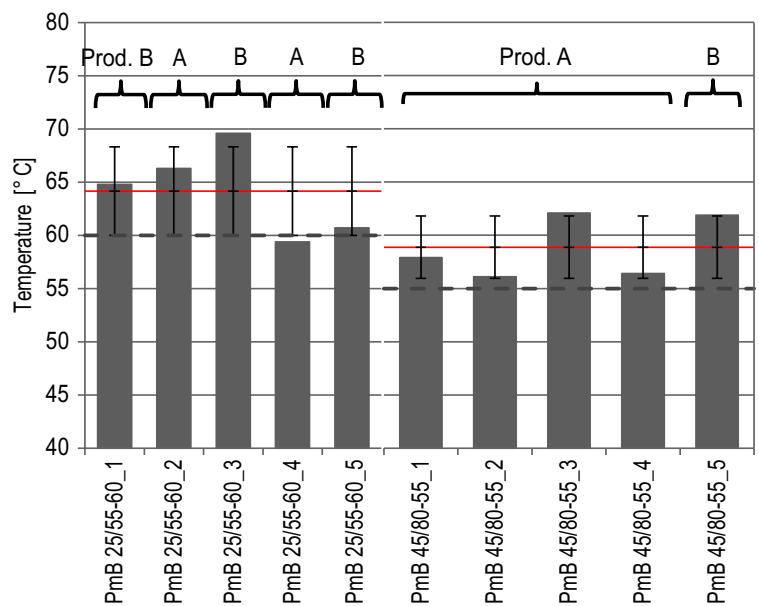

Fig. 5. Polymer modified bitumen softening point 


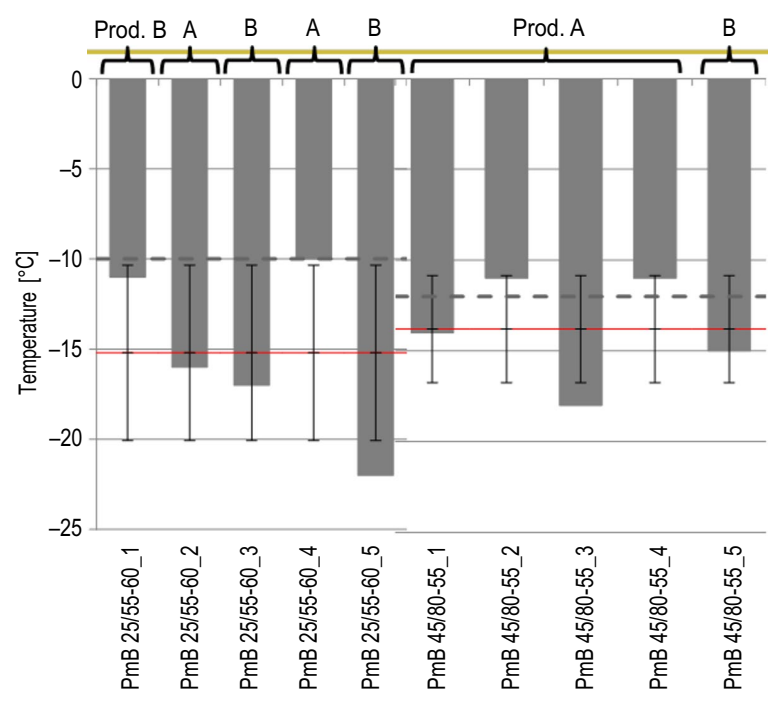

Fig. 6. Polymer modified bitumen Fraass breaking point

According to the European specifications, for the polymer modified bitumen, $50 \%$ elastic recovery is required both before and after RTFO aging.

Binders from the group 45/80-55 meet requirements both before and after aging. Non aged binder 25/55-60 exhibits elastic recovery from 67.5 to $81.0 \%$. However for the same binder, but after RTFO aging, two from five binders does not meet requirements.
Table 1. Elastic recovery for polymer modified bitumen

\begin{tabular}{ccc}
\hline Binders & $\begin{array}{c}\text { Elastic recovery } \\
\text { at } 25{ }^{\circ} \mathrm{C} \\
{[\%]}\end{array}$ & $\begin{array}{c}\text { Elastic recovery after } \\
\text { RTFO at } 25^{\circ} \mathrm{C} \\
{[\%]}\end{array}$ \\
\hline PmB 25/55-60_1 & 67.5 & - \\
\hline PmB 25/55-60_2 & 82.5 & $78.0^{*}$ \\
\hline PmB 25/55-60_3 & 75.0 & - \\
\hline PmB 25/55-60_4 & 81.0 & $78.0^{*}$ \\
\hline PmB 25/55-60_5 & 75.5 & 76.0 \\
\hline PmB 45/80-55_1 & 76.5 & 78.0 \\
\hline PmB 45/80-55_2 & 78.5 & 75.5 \\
\hline PmB 45/80-55_3 & 84.0 & 81.5 \\
\hline PmB 45/80-55_4 & 61.5 & 71.0 \\
\hline PmB 45/80-55_5 & 86.0 & 81.0 \\
\hline
\end{tabular}

* sample broke while stretching

Although it is not required by the specifications, elastic recovery test was also conducted for unmodified bitumen (results are not shown in this paper due to the space limitation). Based on those tests it can be concluded, that hard binders 20/30, both before and after aging, exhibit broke during stretching while testing for the elastic recovery. Non-aged softer binders 35/50 shown elastic recovery of 11 to $16 \%$ and after aging $50 \%$ of those binders had zero elastic recovery value. Binders $50 / 70$ before and after aging exhibit elastic recovery of 10 to $16 \%$.

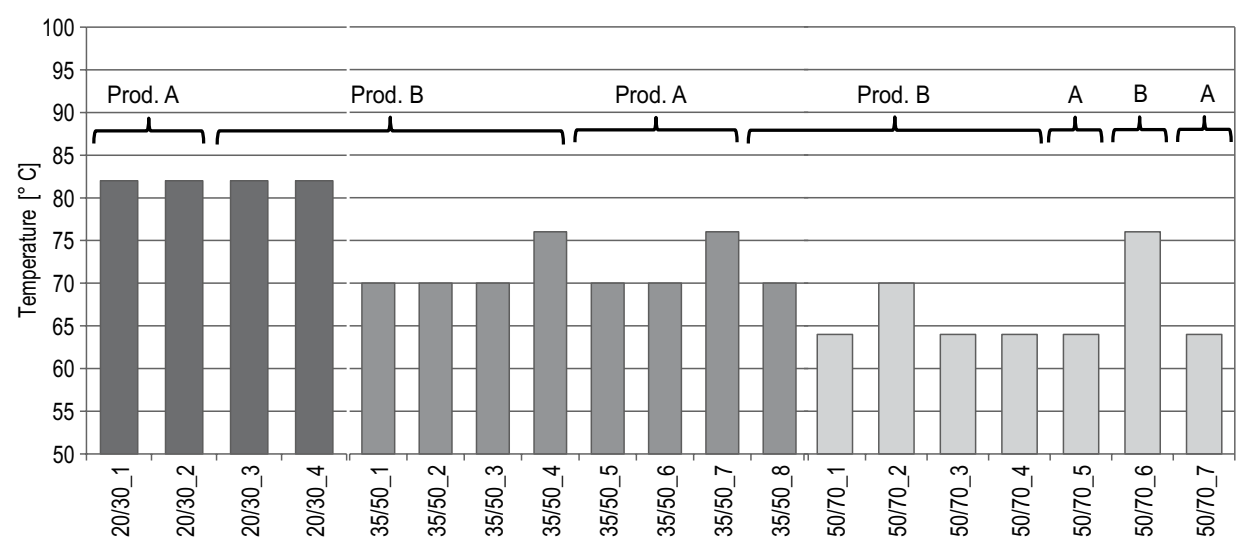

Fig. 7. Upper limit of the performance grade temperature for unmodified bitumen

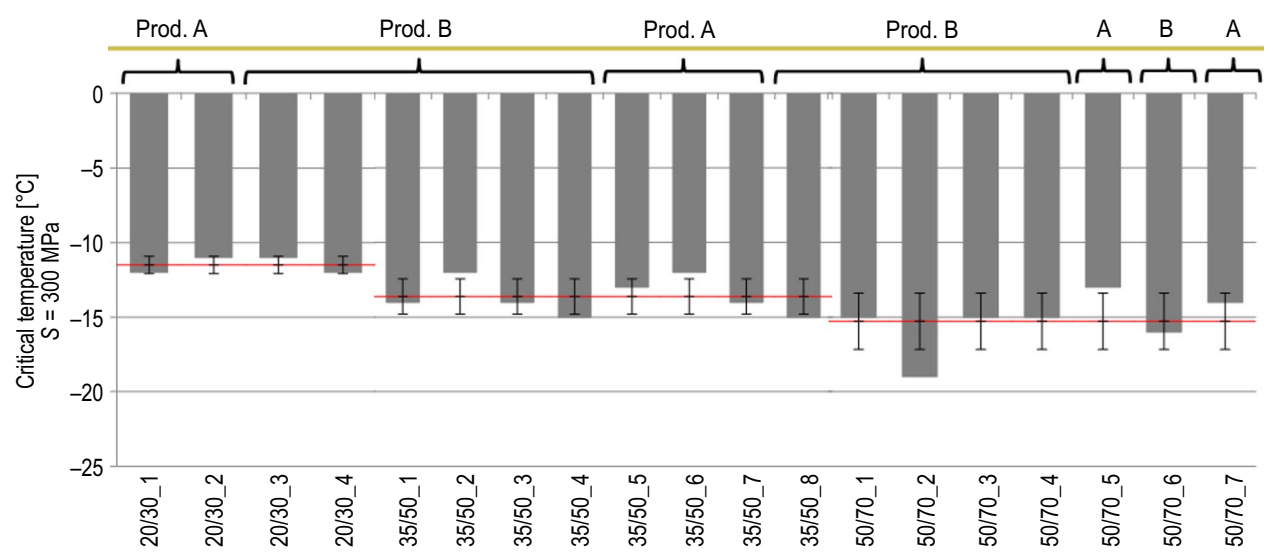

Fig. 8. Unmodified bitumen critical temperature according to BBR ( $S=300 \mathrm{MPa})$ 


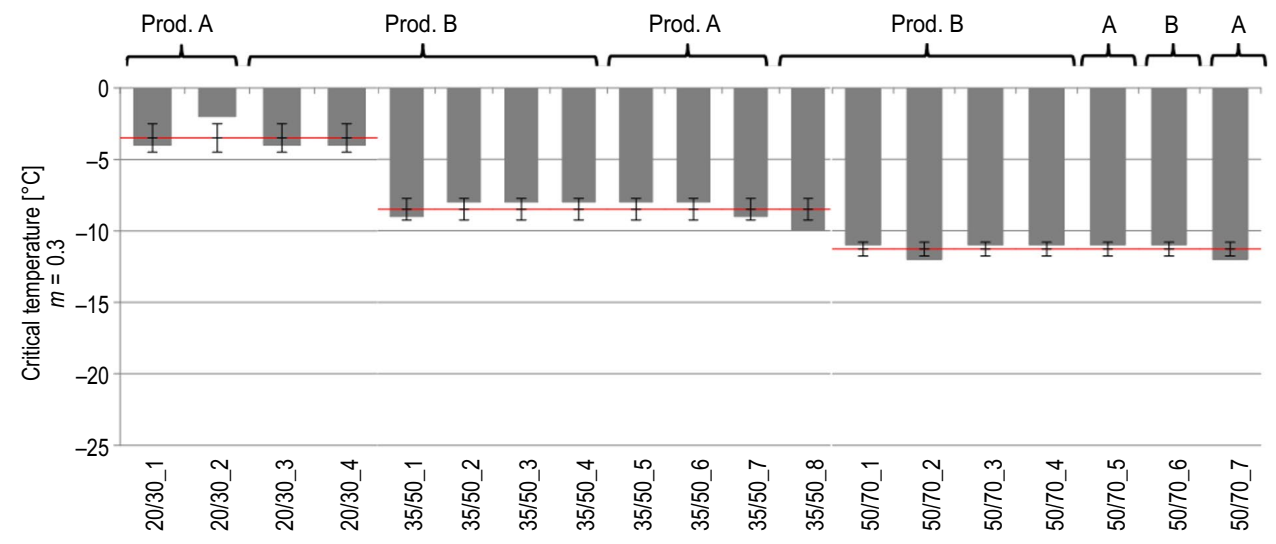

Fig. 9. Unmodified bitumen critical temperature according to BBR $(m=0.300)$

\subsection{Rheological tests}

Rheological tests conducted in wide temperature range and loading time, allows for the viscoelastic properties assessment, both in low and high exploitation temperatures. Good measures of the rheological properties are stiffness modulus $S$, complex modulus $\mathrm{G}^{*}$ and phase angle $\delta$. Complex modulus $\mathrm{G}^{*}$ corresponds to binder resistance for deformation, is time dependent and consists of both viscous (loss modulus G") and elastic (storage modulus G') parts. The complex shear modulus can be expressed by following equations ( $\mathrm{Lu}$, Isacsson 1997):

$$
\begin{gathered}
G^{*}=G^{\prime}+i G^{\prime \prime}=\sqrt{G^{2}+G^{\prime \prime 2}} ; \\
G^{\prime}=\left|G^{*}\right| \cdot \cos \delta ; \\
G^{\prime \prime}=\left|G^{*}\right| \cdot \sin \delta .
\end{gathered}
$$

Phase angle $\delta$ is a measure of delay between strain and stress and can be expressed by:

$$
\tan \delta=G^{\prime \prime} / G^{\prime} .
$$

As a results of dynamic shearing, it can be obtained value of $\mathrm{G}^{*} / \sin \delta$ which is a rutting indication used in $\mathrm{Su}$ perpave requirements. According to Superpave requirements, for the binders in viscoelastic stage working in high temperature, this value should be greater than:

- $\mathrm{G}^{*} / \sin \delta \geq 1.00 \mathrm{kPa}$ for unaged binder;

- $\mathrm{G}^{*} / \sin \delta \geq 2.20 \mathrm{kPa}$ for the RTFO aged binder.

Based on the $\mathrm{G}^{*} / \sin \delta$ value and Superpave requirements, upper limit of the performance grade temperature has been determined, as it is shown in Figure 7 for unmodified bitumen and in Figure 10 for polymer modified bitumen.

Based on the analysis of test results presented in Figures 7 and 10 it can be concluded, that all binders shown upper limit of the performance grade temperature above $64{ }^{\circ} \mathrm{C}$. Higher temperature $\left(82^{\circ} \mathrm{C}\right)$ was obtained for unmodified bitumen 20/30 and polymer modified bitumen PmB 25/55-60. High upper limit of the performance grade temperature, determined using DSR apparatus, indicate high rutting resistance.

For the binders in low temperature in accordance to Superpave requirements (using BBR apparatus) value of critical temperature were determined as a temperature greater than the one corresponding to:

- $S=300 \mathrm{MPa}$ for long-term (PAV) aged binder;

- $m=0.3$ for long-term (PAV) aged binder.

Stiffness modulus $S$ and $m$ parameter (slope of the stiffness curve) can be expressed by the following equations (AASHTO T 313-10 2010):

$$
\begin{gathered}
S(t)=\frac{P L^{3}}{4 b h^{3} \delta(t)} \\
|m(t)|=\frac{d[\log S(t)]}{d[\log (t)]} .
\end{gathered}
$$

In the Eqn (5) $P$ is a constant load, $L$ is a span length, $b$ and $h$ are width and thickness of the beam and $\delta(t)$ is a deflection of the beam.

Critical temperatures determined in BBR apparatus are presented in Figures 8 and 9 for unmodified bitumen and in Figures 11 and 12 for polymer modified bitumen. Stiffness modulus $S$ and logarithmic creep rate $m$-value were measured at 60 seconds of time loading. As a critical temperature it was assumed here (based on the ASTM D6373-13 (2013)) temperature corresponding to $S=300 \mathrm{MPa}$ and $m=0.300$ lowered by $10^{\circ} \mathrm{C}$.

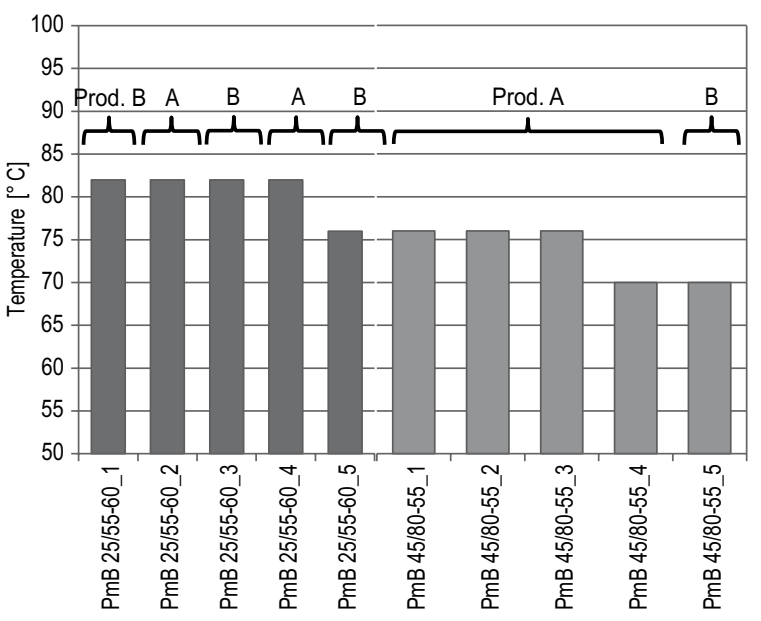

Fig. 10. Upper limit of the performance grade temperature for polymer modified bitumen 


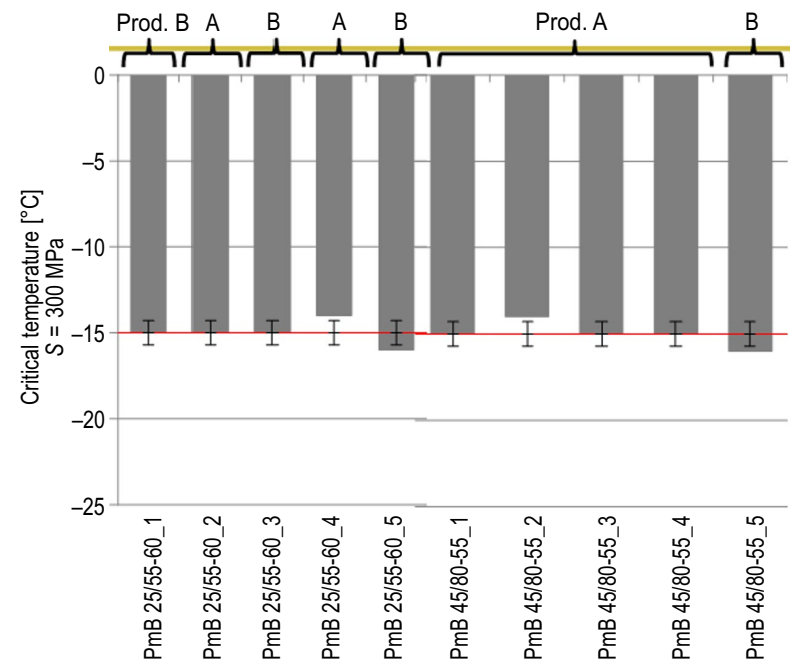

Fig. 11. Polymer modified bitumen critical temperature according to $\mathrm{BBR}(S=300 \mathrm{MPa})$

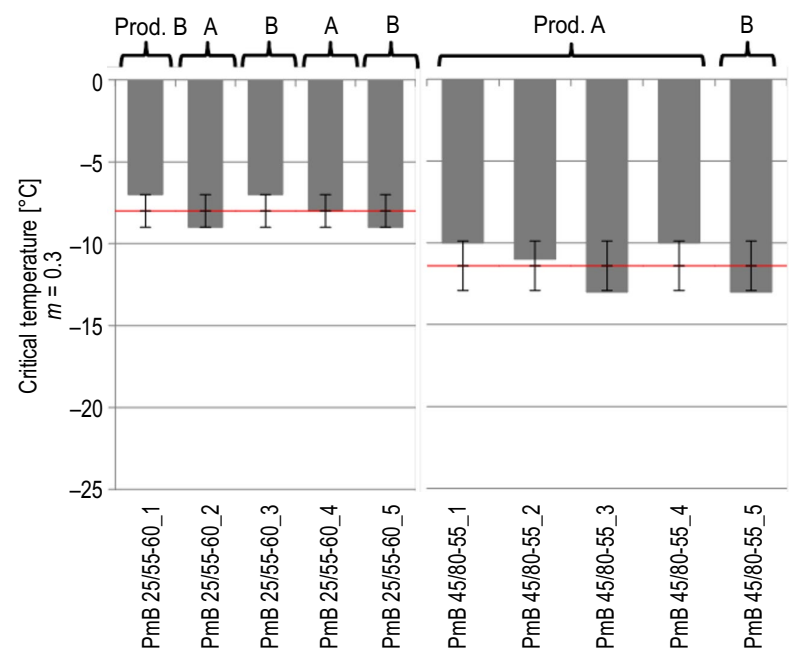

Fig. 12. Polymer modified bitumen critical temperature according to $\mathrm{BBR}(m=0.300)$

Based on the conducted analysis of critical temperature, it was concluded that binders does have a not favourable low temperature properties, especially when laboratory test results would be compared with the typical winter pavement temperatures in Poland (from $-28{ }^{\circ} \mathrm{C}$ to $-34{ }^{\circ} \mathrm{C}$, depending on the geographical location). In addition, it has to be noted, that large differences are presented between critical temperatures obtained using $S$ and $m$ parameters. Critical temperatures determined based on the $m$ parameter are one to two classes higher (unfavourable) than critical temperatures based on the $S$ parameter.

\section{Microstructure of the polymer modified bitumen}

Results of image analysis with fluorescent microscope for the selected polymer modified bitumen are shown in Figure 13. Figures 13a) and 13c) present microstructure of binder from producer A while Figures 13b) and 13d) are microstructure of binder from producer $\mathrm{B}$.

Microstructure of polymer modified bitumen was evaluated in accordance to EN 13632 (2010) specifications based on the continuity and homogeneity of the polymer phase as well as size and shape of the polymer particles using previously developed methodology (Król 2008). In all binders, polymer particles were dispersed in binder matrix. Morphology of polymer modified bitumen shown on Figures 13a) and 13b) presents different shape of particle. Probably different polymer type was used for modification and those differences in particles swelling occur different morphology but that binder still can be classified as a homogeneous.

All industrial modified bitumens with grain structure and round particles smaller than $10 \mu \mathrm{m}$ are classified as homogenous mixes (Figures $13 \mathrm{~b}$ ) and d)). Polymer modified bitumen with elongated polymer particles or rounded polymer particles connected with chains: two samples for PmB 25/55-60 and one sample for 45/80-55 (Figures 13a) and 13c)) have been found as a binder with to low level of elastic recovery.

\section{Fractional composition}

Results of fractional composition analysis are shown in Table 2. Binders were separated using selected solvents according to the Lysychina test method (Lysychina 1949) into three fractions: asphaltens, resins and oils (malthens). Road asphalt binders of the sol-gel rheological type, should exhibit following fractional composition (Kolbanovskaja, Michajłov 1973):

- asphaltens $20 \%$ to $23 \%$;

- resins $30 \%$ to $40 \%$

- oils $45 \%$ do $50 \%$.

Sol-gel asphalts have expanded structure of asphaltens stabilized with thick layers of resins. Such binders exhibit optimal properties for their application in asphalt roads.

Based on the analysis of test results of fractional composition of binder 20/30 it can be noticed, that there is high content of asphaltens.
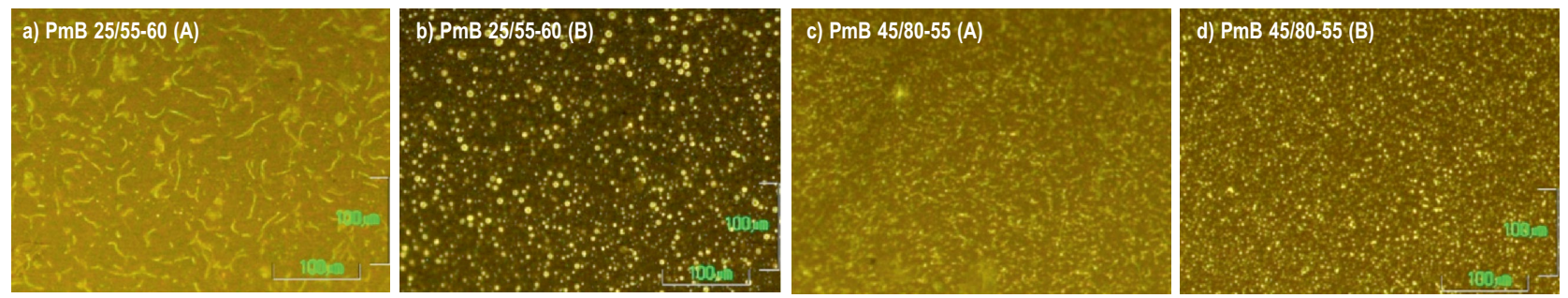

Fig. 13. Microstructure of the polymer modified bitumen 
Table 2. Fractional composition of unmodified bitumen

\begin{tabular}{|c|c|c|c|c|c|c|c|}
\hline \multirow{3}{*}{ Binder type } & \multicolumn{7}{|c|}{ Fractional composition } \\
\hline & \multicolumn{2}{|c|}{ Asphaltens } & \multicolumn{2}{|c|}{ Resins } & \multicolumn{2}{|c|}{ Oils } & \multirow{2}{*}{$\begin{array}{c}\text { Resins/ } \\
\text { asphaltens ratio }\end{array}$} \\
\hline & value & average & value & average & value & Average & \\
\hline 20/30_1 & 21.47 & \multirow{4}{*}{22.47} & 44.69 & \multirow{4}{*}{41.42} & 33.84 & \multirow{4}{*}{36.12} & \multirow{4}{*}{1.84} \\
\hline $20 / 30 \_2$ & 20.85 & & 38.28 & & 40.87 & & \\
\hline $20 / 30 \_3$ & 23.25 & & 41.87 & & 34.89 & & \\
\hline $20 / 30 \_4$ & 24.29 & & 40.84 & & 34.88 & & \\
\hline 35/50_1 & 20.07 & \multirow{8}{*}{19.31} & 43.85 & \multirow{8}{*}{41.01} & 36.09 & \multirow{8}{*}{39.68} & \multirow{8}{*}{2.12} \\
\hline $35 / 50 \_2$ & 18.58 & & 45.20 & & 36.22 & & \\
\hline $35 / 50 \_3$ & 16.85 & & 42.78 & & 40.37 & & \\
\hline $35 / 50 \_4$ & 16.68 & & 41.42 & & 41.91 & & \\
\hline $35 / 50 \_5$ & 20.24 & & 41.10 & & 38.67 & & \\
\hline 35/50_6 & 21.70 & & 38.31 & & 40.00 & & \\
\hline 35/50_7 & 18.47 & & 36.16 & & 45.37 & & \\
\hline $35 / 50 \_8$ & 21.90 & & 39.29 & & 38.82 & & \\
\hline 50/70_1 & 14.91 & \multirow{7}{*}{16.86} & 40.74 & \multirow{7}{*}{41.91} & 44.36 & \multirow{7}{*}{41.24} & \multirow{7}{*}{2.48} \\
\hline $50 / 70 \_2$ & 19.47 & & 41.28 & & 39.26 & & \\
\hline $50 / 70 \_3$ & 18.67 & & 40.90 & & 40.44 & & \\
\hline $50 / 70 \_4$ & 14.81 & & 43.85 & & 41.35 & & \\
\hline $50 / 70 \_5$ & 15.26 & & 43.35 & & 41.40 & & \\
\hline $50 / 70 \_6$ & 18.11 & & 39.51 & & 42.38 & & \\
\hline $50 / 70 \_7$ & 16.79 & & 43.73 & & 39.48 & & \\
\hline
\end{tabular}

Content of asphaltens can be further related with deep oxidation process of such a binder type. Oxidation of 20/30 binder changes composition towards positively higher amount of asphaltens (those increasing rutting resistance), although oils and resins content decreases. Such binders can exhibit lower low temperature cracking resistance.

For eight analysed 35/50 bitumens, asphaltens' content varies between $17 \%$ to $22 \%$. Similar variations can also be noticed for resins and oils. Oil content is lowered by about $7 \%$ in respect to optimal values for sol-gel asphalt according to Kolbanovskaja and Michajłov (1973). It can results in lower asphalt pavement resistance to low temperatures but improved temperature susceptibility.

In group of asphalt binders 50/70, rather high variations in asphaltens content can be noticed. In addition, these asphalts demonstrate low content of asphaltens and oils. Resins content in those seven binders is stable and close to the highest limit according to (Kolbanovskaja, Michajłov 1973). Such a binder can exhibit deteriorated (increased) temperature susceptibility.

For polymer modified bitumen fractional composition criteria from unmodified bitumen shell not be used. Testing of fractional composition of modified bitumen using Lysychina method is not suitable since various solvents used in this method to separated fractions can, in different level, dissolve polymer.

\section{Discussion and conclusions}

Polish climatic conditions include cold winters and hot summers along with high frequency of freezing and thawing cycles (more than 100 per year), which neces- sitate the use of bituminous binders with a wide viscoelastic temperature range.

Based on the tests conducted and analysis of the unmodified and polymer modified bituminous binders produced in Poland, the following conclusions can be drawn:

1. The bituminous binders tested in this study meet all of the current European specifications.

2. All bituminous binders demonstrate very good performance in terms of their resistance to the high temperature distress (resulting in high rut resistance) and very divers' resistance to thermal cracking.

3 . Most of the tested polymer modified bitumens exhibit high value of the elastic recovery, which confirms results from microstructure image analysis (homogenous matrix with rounded particles was found in this analysis). Polymer modified bitumen, PmB 25/55-60, from one of the producers, shows lower level of elastic recovery for short-term aged binder (RTFO-aged). In addition, those binders have a rather atypical microstructure, which may be attributed to, most likely, improper modification technique.

4. Regardless of binder producer, bituminous within the same hardness group showed different low and high temperature properties.

5. Although the binders tested meet the European specifications, they exhibited a diverse range of rheological properties, even when compared within the same hardness and producer group.

Finally, it may be concluded that binders used for the road construction in Poland have good rut resistance and 
inadequate low temperature resistance. For the Polish climatic conditions it may be beneficial to decrease the upper functional temperature limits by $10-20^{\circ} \mathrm{C}$ and extend whole viscoelastic temperature range by $10-15{ }^{\circ} \mathrm{C}$.

It was found that assessment of low temperature properties of bituminous binders is quite problematic. Tests according to Fraass and Bending Beam Rheometer methods do not provide complete answer regarding the low temperature properties, in particular the boundary temperature between viscoelastic and elastic stages. BBR test method seems to be currently one of the best methods to characterize low temperature properties of bituminous binder. However, critical temperature determined in BBR apparatus according to the stiffness modulus $S$ was significantly different that temperature determined according to the $m$ parameter.

Divers' properties of modified and unmodified bituminous binders can be attributed to the unstable properties of crude oil from which the binder was produced.

\section{Acknowledgement}

This work was supported by the Polish General Directorate for National Roads and Motorways. The contents of this paper reflect the views of the authors, who are responsible for the facts and the accuracy of the data presented herein, and do not necessarily reflect the official views or policies of the Polish General Directorate for National Roads and Motorways, nor do the contents constitute a standard, specification, or regulation.

The authors wish to express their gratitude to $\mathrm{Dr}$ Ayesha Shah of Purdue University for her in-depth discussions.

\section{References}

AASHTO T 313-10 standard method of test for determining the flexural creep stiffness of asphalt binder using the bending beam rheometer (BBR). American Association of State and Highway Transportation Officials, USA, 2010. 15 p.

AASHTO TP 92-11 standard method of test for determining the cracking temperature of asphalt binder using the asphalt binder cracking device $(A B C D)$. American Association of State and Highway Transportation Officials, USA, 2011. $12 \mathrm{p}$.

ASTM D6373-13 standard specification for performance graded bituminous binder. American Society for Testing and Materials (ASTM), USA, 2013. 5 p.

Bahia, H.; Hanson, M.; Zeng, H.; Zhai, M.; Khatri A.; Anderson, M. 2001. Characterization of modified bituminous binders in Superpave mix design. NCHRP Report No 459. TRB, National Research Council, Washington, D.C., USA. 54 p.

Behzadfar, E.; Hadzikiriakos, S. 2013. Viscoelastic properties and constitutive modelling of bitumen, Fuel 108: 391399. http://dx.doi.org/10.1016/j.fuel.2012.12.035

Bražiūnas, J.; Sivilevičius, H. 2010. The bitumen batching system's modernization and its effective analysis at the asphalt mixing plant, Transport 25(3): 325-335. http://dx.doi.org/10.3846/transport.2010.40

D'Angelo, J. 2010. New high-temperature binder specification using multistress creep and recovery. Development in bituminous binder specifications. Transportation Research
Circular E-C147. Washington: Transportation Research Board. $86 \mathrm{p}$.

EN 1426:2007 Bitumen and bituminous binders - determination of needle penetration. Brussels: European Committee for Standardization, 2007. $7 \mathrm{p}$.

EN 1427:2007 Bitumen and bituminous binders - determination of the softening point - Ring and Ball method. Brussels: European Committee for Standardization, 2007. 8 p.

EN 12591:2009 Bitumen and bituminous binders - specifications for paving grade bitumens. Brussels: European Committee for Standardization, 2009. $10 \mathrm{p}$.

EN 13398:2010 Bitumen and bituminous binders - determination of the elastic recovery of modified bitumen. Brussels: European Committee for Standardization, 2007. 9 p.

EN 13632:2010 Bitumen and bituminous binders - visualisation of polymer dispersion in polymer modified bitumen. Brussels: European Committee for Standardization, 2010. $13 \mathrm{p}$.

EN 14023:2010 Bitumen and bituminous binders - specification framework for polymer modified bitumens. Brussels: European Committee for Standardization, 2010. 11 p.

EN 14770:2012 Bitumen and bituminous binders - determination of complex shear modulus and phase angle - Dynamic Shear Rheometer (DSR). Brussels: European Committee for Standardization, 2012. $11 \mathrm{p}$.

EN 14771:2012 Bitumen and bituminous binders - determination of the flexural creep stiffness - Bending Beam Rheometer (BBR). Brussels: European Committee for Standardization, 2012. $11 \mathrm{p}$

Eurobitume. 2011. Physical differentiation between air-rectified and oxidised bitumens. Eurobitume, 2011 [online], [cited 11 March 2013]. Available from Internet: http://www.eurobitume.eu/system/files/Differentiating-air-rectified-andoxidised-bitumens 0. pdf

Gaweł, I.; Pilat, J.; Radziszewski, P.; Niczke, Ł.; Król, J.; Sarnowski, M. 2010. Bitumen fluxes of vegetable origin, Polimery/Polymers 55(1): 55-60.

Kolbanovskaja, A. S.; Michajłov, V. V. 1973. Road bitumens. Moskow: Transport. 235 p. (in Russian).

Król, J. 2008. New method of analysis of polymer modified bitumen microstructure, Drogi i Mosty 4: 23-46.

Lysychina, A. J. 1949. Novyj metod opredeleni gruppovogo sostava bitumov $i$ puti bole drobnogo rozdelenia bitumov na otdielnye komponenty. Moskwa: Dorizdat. 149 p. (in Russian).

McDaniel, R. S.; Leahyl, R. B.; Huber, G. A.; Moulthrop, J. S.; Ferragut, T. 2011. The superpave mix design system: anatomy of a research program. NCHRP Final Report, Document No 186. Washington: Transportation Research Board. $172 \mathrm{p}$.

McGennis, R. B.; Shuler, S.; Bahia, H. U. 1994. Background of SUPERPAVE bituminous binder test methods. Report No. FHWA-SA-94-069. Federal Highway Administration, Washington, D.C. 91 p.

Piłat, J.; Król, J.; Błażejowski, K.; Kowalski, K.; Sarnowski, M. 2009. Evaluation of the bituminous binder flexural creep stiffness using bending beam rheometer, in the $4^{\text {th }}$ International Conference on Modern Technologies in Highway Engineering, 2009, Poznań, Poland, 344-355.

Pilat, J.; Radziszewski, P. 2010. Nawierzchnie asfaltowe [Asphalt pavements]. Warsaw: Wydawnictwo Komunikacji i Łączności. 68 p.

PN-EN 12591:2010 Bitumen and bituminous binders - Specifications for paving grade bitumens. Warsaw: Polish Committee for Standardization, 2010. $10 \mathrm{p}$

PN-EN 14023:2010 Bitumen and bituminous binders - Specification framework for polymer modified bitumens. Warsaw: Polish Committee for Standardization, 2010. 11 p. 
Radziszewski, P. 2007. Modified asphalt mixtures resistance to permanent deformations, Journal of Civil Engineering and Management 13(4): 307-315.

Radziszewski, P.; Piłat, J.; Kowalski, K. J.; Król, J. 2012. Use of aggregate from glacier deposits in high-traffic asphalt pavements: a Polish experience, The Baltic Journal of Road and Bridge Engineering 7(1): 5-12. http://dx.doi.org/10.3846/bjrbe.2012.01

Radziszewski, P.; Piłat, J.; Kowalski, K.; Król, J.; Sarnowski, M. 2011. Verification of the requirements and viscoelastic assesment methods for unmodified and polymer modified bituminous binders. Report from the project conducted for the Polish General Directorate for National Roads and Motorways. Warsaw, Poland. 56 p.

Read, J.; Whiteoak, D. 2003. The Shell bitumen handbook. London: Thomas Telford Publishing. 460 p.

Sivilevičius, H.; Šukevičius, Š. 2009. Manufacturing technologies and dynamics of hot-mix asphalt mixture production, Journal of Civil Engineering and Management 15(2): 169-179.

http://dx.doi.org/10.3846/1392-3730.2009.15.169-179
Slowik, M. 2012. Modelling of the inverse creep of road bitumen modified with SBS copolymer, The Baltic Journal of Road and Bridge Engineering 7(1): 68-75. http://dx.doi.org/10.3846/bjrbe.2012.10

Lu, X.; Isacsson, U. 1997. Rheological characterisation of styrene-butadiene-styrene copolymer modified bitumen, Construction and Building Materials 11(1): 23-32. http://dx.doi.org/10.1016/S0950-0618(96)00033-5

Yusoff, N. I. M.; Shaw, M. T.; Airey, G. D. 2011. Modelling the linear viscoelastic rheological properties of bituminous binders, Construction and Building Materials 25(5): 2171-2189.

http://dx.doi.org/10.1016/j.conbuildmat.2010.11.086

Piotr RADZISZEWSKI. PhD, DSc, Professor, Head of the Road Materials and Technology Division, Warsaw University of Technology, Poland. An author or co-author of over 160 scientific publications. His research interests include materials technology related to road pavement construction.

Karol J. KOWALSKI. PhD, an Assistant Professor in the Road Materials and Technology Division, Warsaw University of Technology, Poland, and a Scholar of Polish Ministry of Science and Higher Education within outstanding young scientists program. He received his $\mathrm{PhD}$ from Purdue University, West Lafayette, Indiana. He is an active member of Transportation Research Board Committees AFK30 and AFK40 as well as European Cooperation in Science and Technology (COST). He specializes in tire/pavement noise and frictional properties of pavements. His research interests include pavement construction and materials.

Jan B. KRÓL. PhD, an Assistant Professor in the Road Materials and Technology Division, Warsaw University of Technology, Poland and a Scholar of Centre for Advance Study WUT. He specializes in micro- and macro structure of materials and rheological description of bituminous materials. His research interests are focused on pavement construction and bituminous materials.

Michal SARNOWSKI. PhD, an Assistant Professor in the Road Materials and Technology Division, Warsaw University of Technology, Poland. His research interests include the new kinds of asphalt binder modification, adhesion between bitumen and aggregate, water sensitivity of hot mix asphalt and durability of asphalt pavements.

Jerzy PILAT. PhD, DSc, Professor Emeritus in the Road Materials and Technology Division, Warsaw University of Technology, Poland. He is author or co-author of more than 100 journal and book publications. He focuses his research on materials rheology and pavement technology. 